\title{
Homogenizing Advanced Alloys: Thermodynamic and Kinetic Simulations Followed by Experimental Results
}

\author{
Paul D. Jablonski and Jeffrey A. Hawk
}

\author{
(Submitted September 28, 2016; in revised form November 12, 2016; published online November 28, 2016)
}

\begin{abstract}
Segregation of solute elements occurs in nearly all metal alloys during solidification. The resultant elemental partitioning can severely degrade as-cast material properties and lead to difficulties during post-processing (e.g., hot shorts and incipient melting). Many cast articles are subjected to a homogenization heat treatment in order to minimize segregation and improve their performance. Traditionally, homogenization heat treatments are based upon past practice or time-consuming trial and error experiments. Through the use of thermodynamic and kinetic modeling software, NETL has designed a systematic method to optimize homogenization heat treatments. Use of the method allows engineers and researchers to homogenize casting chemistries to levels appropriate for a given application. The method also allows for the adjustment of heat treatment schedules to fit limitations on in-house equipment (capability, reliability, etc.) while maintaining clear numeric targets for segregation reduction. In this approach, the Scheil module within Thermo-Calc is used to predict the as-cast segregation present within an alloy, and then diffusion controlled transformations is used to model homogenization kinetics as a function of time and temperature. Examples of computationally designed heat treatments and verification of their effects on segregation and properties of real castings are presented.
\end{abstract}

Keywords creep and stress rupture, heat treatment, homogenization, mechanical, modeling and simulation, stainless, steel, superalloys

\section{Introduction}

Solidification is a process whereby liquid metal freezes; however, during solidification some solute elements are rejected into the remaining liquid while other elements preferentially diffuse to the solid (Ref 1 ). This causes chemical heterogeneity in the solidified microstructure. Solute segregation is governed by the solidifying phase (or phases) which may not necessarily be the phases present at room temperature or in service. With sufficient segregation an alloy may also form non-equilibrium matrix phases such as austenite in ferritic/martensitic steels or delta ferrite in austenitic steels. The formation of non-equilibrium solid phases further complicates

Disclaimer This report was prepared as an account of work sponsored by an agency of the United States Government. Neither the United States Government nor any agency thereof, nor any of their employees, makes any warranty, express or implied, or assumes any legal liability or responsibility for the accuracy, completeness, or usefulness of any information, apparatus, product, or process disclosed, or represents that its use would not infringe privately owned rights. Reference herein to any specific commercial product, process, or service by trade name, trademark, manufacturer, or otherwise does not necessarily constitute or imply its endorsement, recommendation, or favoring by the United States Government or any agency thereof. The views and opinions of authors expressed herein do not necessarily state or reflect those of the United States Government or any agency thereof.

Paul D. Jablonski and Jeffrey A. Hawk, National Energy Technology Laboratory, United States Department of Energy, Albany, OR. Contact e-mail: paul.jablonski@netl.doe.gov.

the overall microstructural chemistry since elements partition differently based on the phase(s) that are solidifying.

Ferritic/martensitic steel P91 and austenitic 316 stainless steel are good examples of the intricacies of solute segregation. Under equilibrium conditions, Alloy P91 solidifies in the presence of a ferritic (BCC) matrix while 316 solidifies with an austenitic (FCC) matrix (under equilibrium solidification conditions within certain chemistry restrictions). In reality, while P91 may begin solidifying with primary ferrite, eventually solute segregation stabilizes the austenite. As a result, continued solute segregation is governed by austenite growth instead of ferrite growth resulting in distinctly different segregation regions and a primary solid that is solute poor while the last to freeze solid is solute rich. The case of $316 \mathrm{ss}$ is more complicated. Within the alloy specification chemistry, there are certain compositions that form primary delta ferrite while others form intermediate delta ferrite as a result of segregation. A single-alloy chemical specification can thus have multiple non-equilibrium solidification pathways and segregation behavior. Left unaddressed, solute segregation can result in undesirable scatter in performance in such areas as oxidation resistance and long-term mechanical performance (e.g., creep), resulting from various levels of chemical and microstructural heterogeneity.

In alloys designed for high-temperature service, microstructural effects are often the most important since long-term exposure can lead to undesirable phase formation much earlier than expected. After these phases form, concomitant breakdown of microstructural features responsible for strength, creep resistance, grain size control, and oxidation resistance may occur. For example, in Ni-based superalloys, the segregation of $\mathrm{Cr}$ and Mo can lead to the formation of embrittling TCP (topologically close packed) phases. In high-Cr iron-based alloys such as 304 ss and 316 ss, brittle sigma phase may form due to segregation of $\mathrm{Cr}$ (either directly from the solidification process or as a result of exposure at temperature). Finally, Z- 
phase formation in creep-resistant ferritic/martensitic steels significantly decreases creep performance. Z-phase can be stabilized by a number of elements such as $\mathrm{Cr}, \mathrm{Mo}, \mathrm{Nb}, \mathrm{V}$, and N. Danielson (Ref 2) showed that increasing the Cr levels from 9 to 12 weight percent (a compositional change commonly observed in a highly segregated structure) increased the Zphase precipitation rate by a factor of 50, illustrating how sensitive these alloys are to small changes in composition. Furthermore, chemical inhomogeneity can lead to localized variations in phase solvus and recrystallization temperatures both of which produce undesired microstructural non-uniformities. These examples provide very clear evidence of the need to utilize a holistic approach to ensure pathways for alloy degradation are controlled.

To promote chemical homogeneity within the microstructure, and eliminate coring and other undesirable chemistrybased solidification artifacts, heat-resistant alloys must undergo a thorough homogenization treatment prior to any subsequent heat treatment activity, be it solutionizing for nickel superalloys, austenitizing/normalizing for steels, or aging heat treatments to facilitate strength improvements in other alloy systems. In many cases, the solution heat treatment can be skipped if the homogenization heat treatment temperature and cooling rates are adequate.

It is common practice to homogenize heat-resistant castings, especially single-crystal and directionally solidified nickel superalloys used in both power generation and aerospace turbines (Ref 3-5). It is less common to homogenize wrought alloys because many believe the thermo-mechanical processing (TMP) involved sufficiently breaks down the cast microstructure. However, newer heat-resistant alloys for fossil energy applications (e.g., ferritic/martensitic steels, and solid solutionstrengthened, low-volume $\gamma^{\prime}$ fraction nickel superalloys) make significant use of refractory and transition elements to strengthen the matrix and develop complex carbides for grain size control and long-term microstructure stability. The refractory elements, by their nature, segregate radically during solidification by either partitioning to the liquid or diffusing very slowly in the solidified alloy. As a result, solidified structures are characterized by extremely non-uniform matrix composition profiles compared to other systems. TMP operations may do no more than move these regions relative to one another, or in some cases, cause even more severe segregation due to anisotropic deformation. Additionally, reheating and holding steps common in most TMP operations cannot be relied upon for homogenization because there is insufficient time for refractory elements to diffuse. Utilizing a 1-h normalizing sequence after TMP for martensitic heat-resistant steel, for example, does little to further disperse the refractory elements W, Mo, or Co.

Until recently, the process of developing an alloy homogenization has been fairly stagnant. The steps involved typically include identifying the incipient melt temperature of an alloy and estimation of the time at temperature necessary to facilitate solid-state diffusion in the alloy. Accurate estimates of incipient melt point will depend on sampling and measurement technique. Methods include differential scanning calorimetry (DSC) (fairly accurate temperatures but small sample sizes) and isothermal exposure (less accurate temperatures but much larger samples). Solid-state diffusion time estimates are complicated by the fact that there is chemical diffusion involved rather than simple tracer diffusivity; thus, the local chemistry becomes an important factor which changes throughout the process. As discussed previously, there are many factors that must be considered when assessing local chemistry in cast structures, necessitating a more formal manner by which estimates may be made. Thermodynamic and kinetic simulation software, while not perfect, have evolved quite significantly over the past 10 years and can now facilitate time-saving approaches to the developing homogenization heat treatments for heat-resistant alloys.

Given the complex nature of heat-resistant alloys, computationally guided experiments have become a necessity. Computational tools help alloy developers make reasonably accurate predictions of phase equilibria thermodynamics and diffusiondriven kinetics. These predictions provide guidance for alloy processing (including heat treatment) without relying on significant trial and error. In the approach described herein, commercially available thermodynamic and kinetic software has been utilized in a carefully designed algorithm to homogenize complex nickel-based superalloys, as well as austenitic, martensitic, and ferritic steels. Specifically, this approach has led to highly homogenized solid solution-strengthened cast nickel superalloys (Haynes 230, Inconel 617, and Inconel 625), $\gamma^{\prime}$-strengthened nickel superalloys (Nimonic 105, Nimonic 263, Inconel 740, and Haynes 282), austenitic stainless steels (304 and 316), ferritic stainless steels (403, and 441), ferritic/martensitic alloys (P91, P92, and TAF), and other experimental alloys. Given this success, the homogenization sequence is now being utilized for every heat-resistant alloy produced at NETL with very good results.

The computational approach (which may be used to homogenize any alloy) will be discussed in broad terms with some specific examples provided. The examples include many of the previously mentioned alloy systems. Discussion as to effectiveness will be provided through microscopy of the microstructures and mechanical property results, primarily through measurement of the creep rupture life.

The present homogenization algorithm utilizes simple microstructural measurements from the as-cast microstructure to scale the degree of segregation in the solidified ingot using the well-known Scheil-Gulliver approach. Overall ingot chemistry information serves as a primary input to DICTRA and Thermo-Calc and is subsequently used along with microstructural measurements to predict the chemical profile evolution over time. The chemical profile information is then used to provide an estimate of the new incipient melt temperature after partial homogenization has taken place. This new incipient melt point can then be used to incrementally increase heat treatment temperatures to achieve high chemical uniformity over less time. This approach can also accelerate the development of homogenization heat treatments for newly developed heatresistant alloys since the only model inputs are easily obtained microstructural and chemical information.

Previous efforts had relied on the alloy solidifying from the melt as a single matrix phase (Ref 6, 7). However, not all alloys solidify in this manner. For example, many ferrous alloys begin to solidify with a BCC crystal structure and finish with an FCC structure. Other alloys start with an FCC structure and finish with a BCC structure. Still other alloys may form a significant amount of second phase such as carbide or some other ordered phase. In these instances, characterizing only the matrix does not adequately capture the overall nuances of the local chemistries found in these alloys. The present algorithmic computational approach calculates the incremental solid chemistry, i.e., the chemistry of each new addition to the solid from 
the overall amount of liquid and its chemistry, as the alloy progresses from the initial stages of solidification through the point when all liquid is converted to solid. In this way, each incremental solid is assembled together subsequently to form an overall chemistry profile that can then be used to calculate the interdiffusion required to bring about homogenization. The description of the solid chemistry flows from that of the liquid as follows:

Chemistry just before first solid forms: $f_{\mathrm{s}}=0: C_{0}$.

Chemistry when first solid forms:

$C_{\mathrm{s}_{1}}=\frac{\left(C_{\mathrm{o}}-f_{1_{1}} C_{\mathrm{l}_{1}}\right)}{\operatorname{inc} f_{1}}$

Chemistry for each additional solid that forms is given by:

$C_{\mathrm{s}_{1+i}}=\frac{\left(C_{o}-f_{1_{1+i}} C_{\mathrm{l}_{1+i}}-\sum f_{1_{i}} C_{\mathrm{l}_{i}}\right)}{\operatorname{inc} f_{1}}$

where $C_{\mathrm{o}}$ is the overall alloy chemistry for each element; $C_{\mathrm{s}_{1}}$ is the chemistry of the first solid to form; $C_{\mathrm{S}_{1+i}}$ is the chemistry of the $s_{1+i}$ solid to form; $f_{l_{n}}$ is the fraction of $n$th liquid to form; $C_{l_{n}}$ is the composition of the liquid when the $n$th liquid forms; and $\operatorname{inc} f_{1}$ is the incremental fraction of liquid that forms when the $n$th liquid forms. To homogenize an alloy to a high degree requires multiple steps based on redefining this "overall chemistry" for each homogenization step (i.e., specific temperature and time at a given temperature increment) until the required degree of homogenization is reached.

At this point, the Scheil module within Thermo-Calc (Ref 8) is utilized to predict the extent of chemical microsegregation present as a result of alloy solidification. Whenever possible, the actual measured chemistry of the solidified cast alloy is used; however, in many cases the nominal or aim chemistry will suffice. Close attention is given to potent melt point suppression elements such as $\mathrm{C}, \mathrm{Si}$, and $\mathrm{Mn}$. Based upon the chemical segregation predicted, computational kinetic modeling (Ref 9) is then used to design an optimized homogenization heat treatment that flattens the sinusoidal concentration profile of each alloying element within the dendrites of the matrix.

Subsequently, the Scheil module and relevant database from the thermodynamic software (Thermo-Calc) is used to predict the non-equilibrium solidification range of each alloy. Specifically, the Scheil module in the commercial software package (i.e., Thermo-Calc) is an implementation of the Scheil-Gulliver model (Ref 10,11), and in this case assumes that diffusion occurs infinitely fast within the liquid phase and no diffusion occurs in the solid state. The analytical Scheil equation is commonly derived for an idealized system in which the liquidus and solidus are linear with respect to composition. When this is true, $C_{\mathrm{s}} / C_{1}=k$, where $C_{\mathrm{s}}$ is the composition of the solid and $C_{1}$ is the composition of the liquid at a given temperature. When an incremental amount of solid $\left(d f_{\mathrm{s}}\right)$ forms, $C_{\mathrm{s}} d f_{\mathrm{s}}$ solute transfers from the liquid to the solid. As a result, the incremental change in the liquid composition is given by:

$d C_{1}=\left(C_{1}-C_{\mathrm{s}}\right) d f_{\mathrm{s}} /\left(1-f_{\mathrm{s}}\right)$

This equation can be integrated to describe the composition of the liquid as a function of fraction solid $\left(f_{\mathrm{s}}\right)$ formed:

$C_{1}=C_{\mathrm{o}}\left(1-f_{\mathrm{s}}\right)^{(k-1)}$

In the more complicated (and more usual) case in which the liquidus and solidus curves are not linear, $C_{\mathrm{s}}$ and $C_{1}$ will be described analytically with subsequent integration of Eq 3. The Scheil module within the commercial software package (Thermo-Calc) calculates $\Delta f_{\mathrm{s}}, \Delta C_{\mathrm{s}}$ and $\Delta C_{1}$ in a user-defined increment of temperature until a predetermined amount of liquid remains. Fast diffusing elements such as B, C, N, and O can be allowed to back-diffuse within the solid, but this was not considered in the present case. The default results obtained from the Scheil simulation for a given alloy are the amount of solid phase formed versus solidification temperature. Not only does this show how the solidification sequence progresses, it also shows the phases that develop (many are non-equilibrium), as well as the solidification temperature range. However, this is not directly useful in defining the homogenization heat treatment sequence beyond establishing the initial incipient melt temperature. A homogenization heat treatment consists of certain times at certain temperatures to establish the level of chemical uniformity desired. After the Scheil simulation is run, the amount of each alloying element in a given phase present can be determined. In the case of the alloys investigated, the weight fraction of each of the alloying elements in the liquid phase is then calculated as a function of temperature. The liquid-phase chemistry is used to calculate the overall solidphase chemistry as described by Eq 1 and 2. Thus, the chemical segregation that occurs in the solid across a secondary dendrite arm constitutes the undesired microsegregation that needs to be eliminated through an appropriate homogenization heat treatment. Standard metallographic techniques are used to measure the secondary dendrite arm spacing (sdas) of the castings. From these measurements, a value of approximately half the maximum sdas was used as a conservative estimate of the required diffusion distance. The weight fraction of matrix phase was scaled to this distance and used in the DICTRA software, along with the chemistry profiles across the matrix phase. Thus, the positional chemistries were established

\section{Experimental Details}

Typically, the experimental heats were formulated from high-purity raw materials. To date nickel superalloys, austenitic and ferritic-martensitic steels, and high-entropy alloys have been manufactured using this approach. The starting materials for these $7 \mathrm{~kg}$ heats were melted and cast in a vacuum induction furnace (VIM). Typically, molten alloy was cast at $50{ }^{\circ} \mathrm{C}$ superheat above the Thermo-Calc-predicted liquidus temperature for each alloy composition into $100-\mathrm{mm}-$ diameter round graphite molds (Ref 12, 13). When simulating a thick-wall casting, the mold was placed in a secondary container with loose-packed sand around the outside. The sand height was carefully controlled in order to be above the final height of the solidified ingot to promote a slower cooling rate. In those instances where the final casting will be subsequently thermo-mechanically processed into a wrought product, the alloy heats were poured into free standing 75mm-diameter graphite molds. Commercial-scale castings have subsequently been made by multiple methods, including VAR (vacuum arc remelting) and sand casting. The scale of the microstructures in those commercial-sized castings as well as the NETL laboratory castings was subsequently measured using standard metallographic techniques and the sdas in these castings used as the scale of the matrix phase as previously described. 
No attempt was made to optimize the final cast article for shrinkage aside from the addition of a small ingot "hot top" riser in the 75-mm castings. As such, the upper surface in the central portion of the solidified $100-\mathrm{mm}$ castings exhibited significant shrinkage (Fig. 1). The microstructures of the castings were evaluated through standard metallographic techniques, including sectioning, grinding, polishing, and etching followed by optical microscopy. The sdas was measured using a line intercept method. A sample from the casting was then subjected to the homogenization heat treatment for its specific microstructural sdas. A side-by-side comparison of the as-cast and homogenized specimens was provided by mounting them together in the same metallographic mount, thus providing identical metallographic preparation conditions. Whenever possible, mechanical property testing, such as room and elevated temperature tensile tests as well as creep rupture tests, was performed on selected samples following the usual ASTM mechanical testing procedures including E21 for elevated tensile and E139 for creep testing.

\section{Results and Examples}

A variety of alloys have been produced and heat-treated according to the computationally optimized homogenization algorithm. In some cases, multiple examples of the same alloy cast under similar conditions (and thus anticipated to have similar scaled microstructures) have been investigated. Likewise, in some cases the same alloy has been cast at small scale in the laboratory as well as at larger scale in a commercial facility, or perhaps by a different method (or both), thereby providing a range of sdas characteristic lengths. Several of these examples follow.

\subsection{Example 1: Haynes ${ }^{\circledR} 282^{\circledR}$}

Haynes ${ }^{\circledR} 282^{\circledR}$, hereafter Haynes 282, is a relatively new wrought Ni-based superalloy initially developed for the aerospace industry (Ref 14). The alloy has a nominal composition of Ni-19.5Cr-10Co-8.5Mo-2.1Ti-1.5Al with small amounts of $\mathrm{C}$ and $\mathrm{B}$ and prescribed limitations on the amounts of $\mathrm{Fe}, \mathrm{Mn}$, and Si. Haynes 282 has been evaluated for thick-section steam turbine casing and valve body components. These components, because of the size requirements, are most economically made by sand casting. The first trial lots of Haynes 282 were cast into 100-mm-diameter molds using the "enhanced" slow-cooling technique to emulate larger castings (Ref 12,13). The as-cast Haynes 282 ingot chemistry was evaluated using the commercial thermodynamic software packages as outlined in the previous section. A critical parameter important in this approach is the incipient melt point. The initial incipient melt point is given by the Scheil module. However, the incipient melt point changes throughout the homogenization process, and thus, to optimize alloy homogenization it is necessary to iterate the new virtual incipient melting temperature. Using the prescribed algorithms, the homogenization temperature and time at this temperature are adjusted incrementally in order to meet the desired chemical uniformity goals. Metallographic measurements have been used to verify that in typical slowcooled castings the sdas varied between 47 and $96 \mu \mathrm{m}$ for those castings with a diameter of $100 \mathrm{~mm}$. From these measurements, for example, a value of $50 \mu \mathrm{m}$ (or $\sim$ half the maximum sdas length) was used as a conservative estimate of the required diffusion distance. An example of the technique is shown in Fig. 2 which shows the as-solidified profile for Mo along with a schematic representation of a typical dendrite.

As shown, molybdenum segregates to the interdendritic region of this alloy. Note that the inhomogeneity is scaled to half of the sdas. Figure 3 shows the Mo profile in the as-cast state and after several simulated time steps at $1100{ }^{\circ} \mathrm{C}$. This temperature was chosen because it was safely below the estimated non-equilibrium incipient melt temperature, $\sim 1167{ }^{\circ} \mathrm{C}$. After running these simulations, it was evident that even after $80,000 \mathrm{~s}(\sim 22.4 \mathrm{~h})$ at $1100{ }^{\circ} \mathrm{C}$, the Mo has not been substantially homogenized. Evaluating the local chemistry after a shorter time step indicated that the incipient melt temperature had risen, and now approached the equilibrium incipient melt temperature. This fact is advantageous in improving the efficiency of the Haynes 282 homogenization cycle.

For example, after $10,000 \mathrm{~s}(\sim 2.8 \mathrm{~h})$ at $1100{ }^{\circ} \mathrm{C}$ the incipient melt temperature has increased to $\sim 1245^{\circ} \mathrm{C}$, thus allowing the homogenization temperature to be safely raised as well. A second computational evaluation was made with $10 \mathrm{ks}$ at $1100{ }^{\circ} \mathrm{C}$ followed by the remaining time at $1200{ }^{\circ} \mathrm{C}$ (see
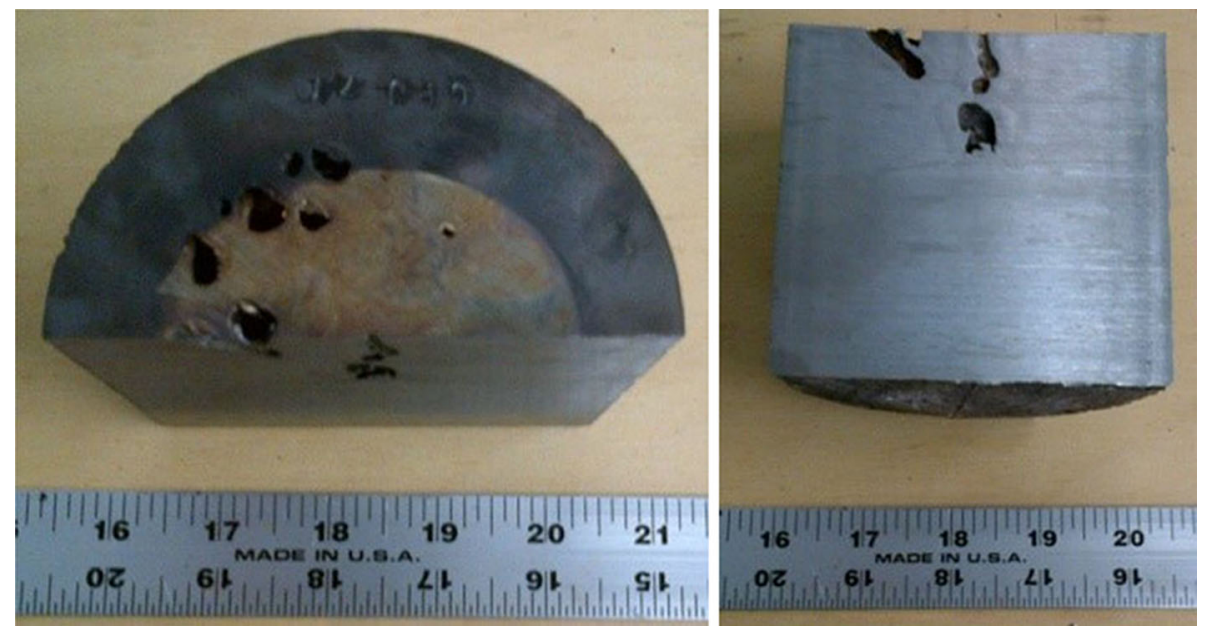

Fig. 1 Example of a casting using the mold design in Ref 12, 13. The left photograph shows the top of the solidified article. The right photograph shows the cross section with extent of shrinkage. This was typical of all materials manufactured in this manner 


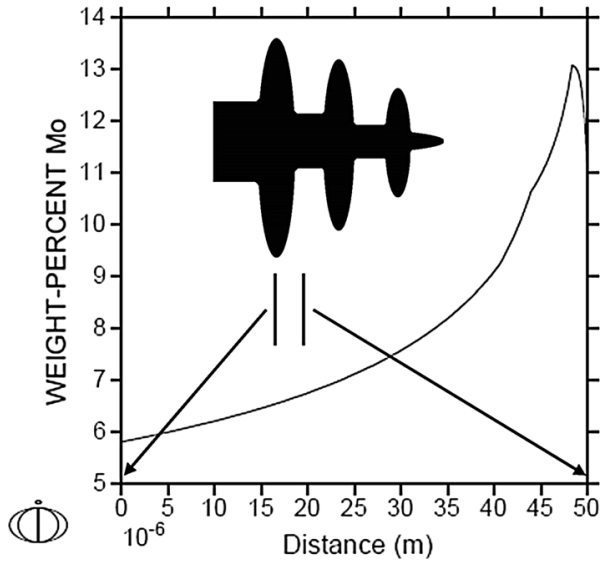

Fig. 2 As-solidified mass change profile of Mo along with a schematic representation of one half the distance between the secondary dendrite arms

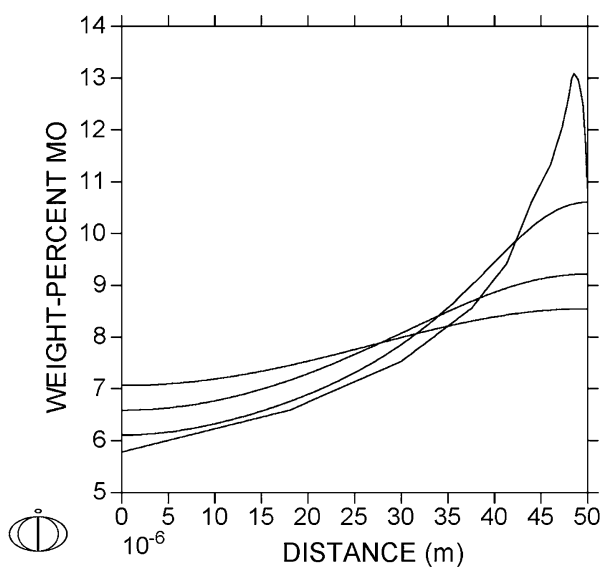

Fig. 3 Mo mass profile in as-solidified condition for one half the secondary dendrite arm spacing and after 10,40 , and $80 \mathrm{ks}$ isothermal exposure at $1100{ }^{\circ} \mathrm{C}$ (as time increases the profile approaches horizontal). Note that substantial inhomogeneity remains even after $80 \mathrm{ks}$ at $1100{ }^{\circ} \mathrm{C}$

Fig. 4). In this case, it is quite evident that the efficiency of the homogenization cycle has greatly improved by incorporating a second, higher-temperature treatment. It should be noted that the choice of temperature margin between the homogenization cycle and the incipient melt point is somewhat arbitrary. Factors considered in the selection of this temperature include the accuracy of the estimated incipient melt point (mainly dependent on the quality of the thermodynamic and kinetic/diffusion databases and degree of accuracy in the measurement of the sdas), furnace temperature control margin, and furnace temperature uniformity (both dependent on available equipment). Other considerations include maximum furnace temperature capability. The impact of the homogenization cycle on the microstructure is shown in Fig. 5, which compares the solidified cast structure with a similar representation of the as-cast and homogenized structure under identical imaging conditions. Clearly, the alloy exhibits less segregation after homogenization. Perhaps more important is the comparison between the homogenized and non-homogenized mechanical properties. Figure 6 show creep rupture performance of the cast, cast and homogenized, and wrought product forms. While

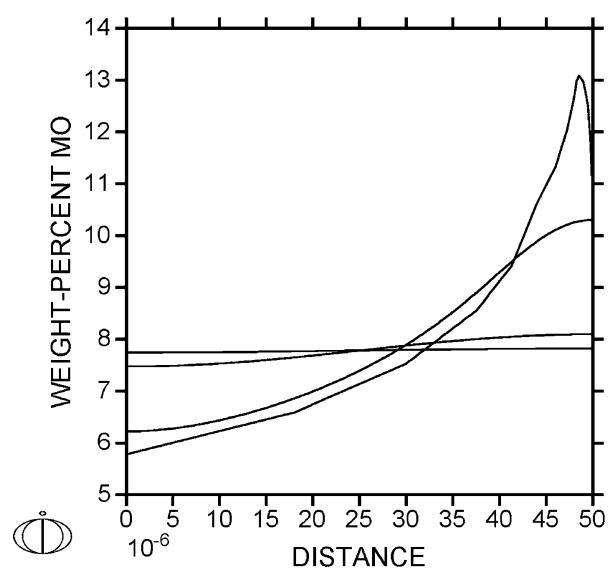

Fig. 4 Mo mass profile in the as-solidified condition for one half the dendrite arm spacing and after 10,40 , and $80 \mathrm{ks}$ total isothermal exposure time. After $10 \mathrm{ks}$ at $1100{ }^{\circ} \mathrm{C}$, the simulation temperature was raised to $1200{ }^{\circ} \mathrm{C}$. Note the substantial improvement in the Mo uniformity over the single temperature simulation (Fig. 3)

the as-cast, homogenized, and heat-treated (to develop $\gamma^{\prime}$ precipitates) castings compared favorably to the wrought material, the non-homogenized cast and heat-treated samples generally did not do as well in terms of creep rupture.

The impact of microstructural scale is significant, if somewhat predictable. Figure 7 shows a plot of the predicted Mo simulation profile after virtual homogenization of as-cast material using sdas of 100,200 , and $400 \mu \mathrm{m}$. It is clear that while modulation in the $100-\mu \mathrm{m}$ Mo profile has "flattened" (i.e., significant reduction in segregation), the same cannot be said for the coarser microstructures. Haynes 282 has been cast on a larger scale, and the measured sdas was on the order of $200 \mu \mathrm{m}$. For Haynes 282, an initial virtual simulation of $3 \mathrm{~h}$ at $1100{ }^{\circ} \mathrm{C}$ raises the incipient melt points to the following: 1245 , 1219 , and $1219^{\circ} \mathrm{C}$ for sdas lengths of 100,200 , or $400 \mu \mathrm{m}$, respectively. Thus, these results clearly show that it gets progressively more difficult to raise the temperature for castings that exhibit coarser microstructures with large representative sdas lengths.

While this has been fundamentally understood for quite some time, it was not until research on this project discovered the underlying reason, i.e., the computational algorithm is based on thermodynamics and kinetics/diffusion that describes the change in incipient melt point after any increment of heat treatment based on the overall solid chemistry. Some advantage can be gained by going to a higher temperature initially as this raises the incipient melt temperature more rapidly. However, for this alloy the equilibrium incipient melt temperature is only on the order of $1260{ }^{\circ} \mathrm{C}$, so the upper furnace temperature can become the limiting homogenization processing factor. Successful homogenization heat treatment cycles based on this approach have been developed for large castings of Haynes 282 using the following homogenization schedules:

a) $1130{ }^{\circ} \mathrm{C} / 3 \mathrm{~h}+1200{ }^{\circ} \mathrm{C} / 3 \mathrm{~h}+1210{ }^{\circ} \mathrm{C} / 14 \mathrm{~h}(135 \mathrm{~kg}$ step block casting)

b) $1100{ }^{\circ} \mathrm{C} / 6 \mathrm{~h}+1200{ }^{\circ} \mathrm{C} / 48 \mathrm{~h}(450 \mathrm{~kg}$ step block casting)

c) $1133{ }^{\circ} \mathrm{C} / 4 \mathrm{~h}+1190{ }^{\circ} \mathrm{C} / 8 \mathrm{~h}+1223{ }^{\circ} \mathrm{C} / 30 \mathrm{~h} \quad(4,500 \mathrm{~kg}$ ESR/VAR ingot)

d) $1125^{\circ} \mathrm{C} / 1 \mathrm{~h}+1160{ }^{\circ} \mathrm{C} / 3 \mathrm{~h}+1190{ }^{\circ} \mathrm{C} / 6 \mathrm{~h}+1200{ }^{\circ} \mathrm{C} / 10$ (635 kg centrifugal casting) 


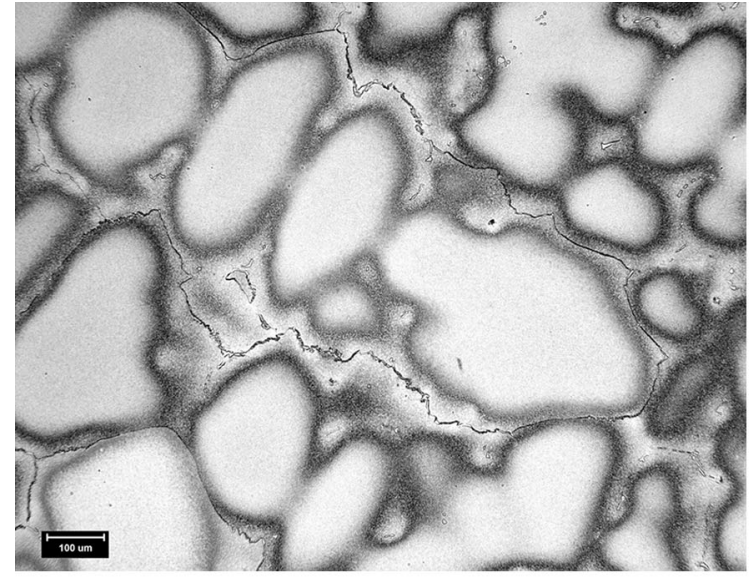

(a)

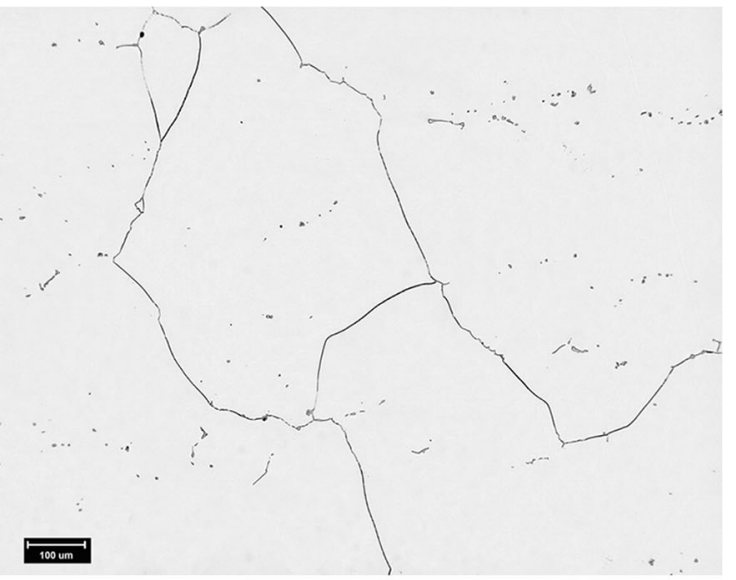

(b)

Fig. 5 Examples of the as-cast (a) and homogenized (b) microstructure of Haynes 282. Dendritic coring (i.e., element segregation) is clearly visible on the left, while only grain boundaries and carbides are visible on the right. Micron markers indicate $100 \mu \mathrm{m}$

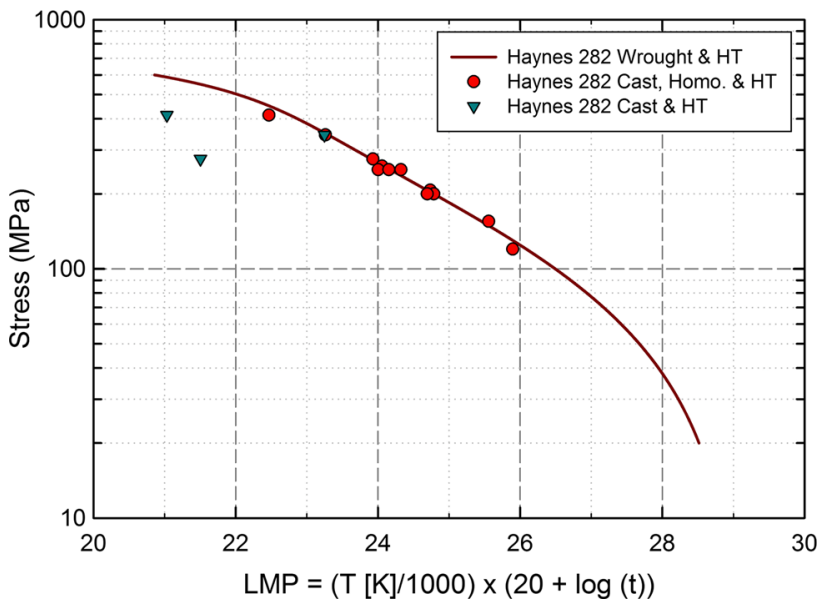

Fig. 6 Larson-Miller parameter plot for Haynes 282 comparing the cast and heat-treated (inverted triangles) to cast, homogenized and heat-treated (solid circles) to that of the wrought-processed and heattreated (solid line). Note that the cast, homogenized, and heat-treated version of Haynes 282 compares favorably to that of the wrought version of Haynes 282 in terms of creep rupture life, while those tests of the cast alloy without homogenization generally do not. [Wrought data on creep were extracted from a variety of references, e.g., Ref 14 , as well as from actual testing of Haynes ${ }^{\circledR} 282^{\circledR}$ (Ref 19)]

These four heat treatment schedules were designed for commercial heat treating furnaces and subsequent results verified the variability and adaptability of this approach. The homogenization cycles produced good material which was verified from metallographic analysis and mechanical property evaluation.

\subsection{Example 2: NIMONIC ${ }^{\circledR}$ Alloy 263}

NIMONIC ${ }^{\circledR}$ Alloy 263, hereafter alloy 263, is another wellestablished Ni-based superalloy with a nominal composition of $\mathrm{Ni}-20 \mathrm{Cr}-20 \mathrm{Co}-5.85 \mathrm{Mo}-2.4 \mathrm{Ti}-0.3 \mathrm{Al}$ with small amounts of $\mathrm{C}$ and $\mathrm{B}$ as well as composition limitations on $\mathrm{Fe}, \mathrm{Mn}$, and $\mathrm{Si}$ (Ref 15). Similar-sized ingots to that of Haynes 282 (both small and large) were cast using alloy 263 chemistry. The length scale of

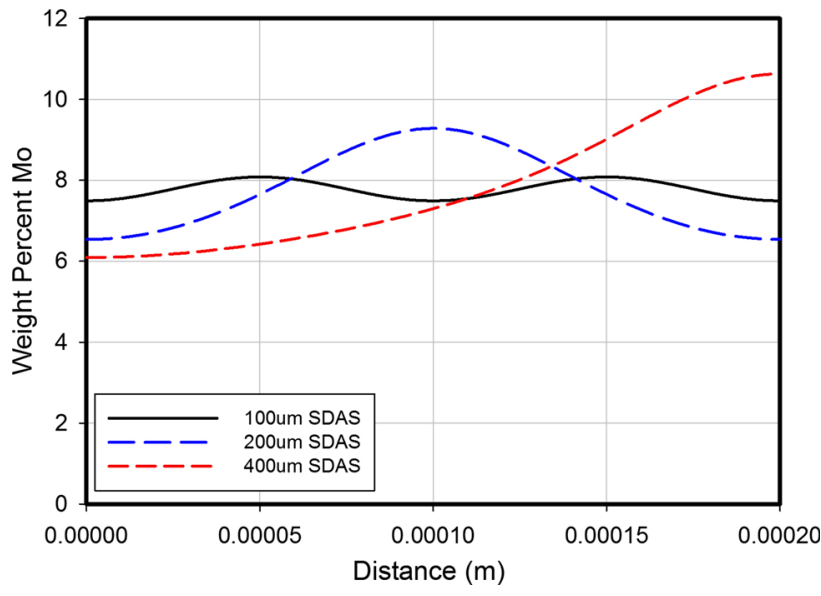

Fig. 7 Mo mass profile (in weight percent) for various sdas lengths for Haynes 282 after homogenizing at $1100{ }^{\circ} \mathrm{C} / 3 \mathrm{~h}+1200{ }^{\circ} \mathrm{C} / 9 \mathrm{~h}$. For this homogenization cycle, the degree of homogenization is dependent on the coarseness of the as-cast dendrite structure

sdas in the small castings was once again approximately $100 \mu \mathrm{m}$. The larger castings had sdas approximately equal to $200 \mu \mathrm{m}$. The homogenization cycles developed for alloy 263 were:

a) $1100{ }^{\circ} \mathrm{C} / 3 \mathrm{~h}+1200{ }^{\circ} \mathrm{C} / 9 \mathrm{~h}$ (laboratory-scale castings)

b) $1100{ }^{\circ} \mathrm{C} / 1 \mathrm{~h}+1200{ }^{\circ} \mathrm{C} / 4 \mathrm{~h}+1250{ }^{\circ} \mathrm{C} / 18 \mathrm{~h}$

c) $1100{ }^{\circ} \mathrm{C} / 1 \mathrm{~h}+1190{ }^{\circ} \mathrm{C} / 44 \mathrm{~h}$

d) $1100{ }^{\circ} \mathrm{C} / 1 \mathrm{~h}+1200{ }^{\circ} \mathrm{C} / 4 \mathrm{~h}+1232{ }^{\circ} \mathrm{C} / 22 \mathrm{~h}$

with (b), (c), and (d) homogenization cycles for a $450-\mathrm{kg}$ step block but with limitations on furnace capability, (c) and (d). For example, one commercial furnace had an upper temperature of $1190{ }^{\circ} \mathrm{C}$, while another was able to go to $1232{ }^{\circ} \mathrm{C}$. Following the homogenization schedule given for (b), (c), and (d) gave for Mo a variation of 91.4-108.5\% using (b) with $23 \mathrm{~h}$ in the furnace; 91.6-108.3\% using (c) with $45 \mathrm{~h}$ in the furnace; and $91.1-108.8 \%$ using (d) with $27 \mathrm{~h}$ in the furnace. Each homogenization cycle resulted in successful homogenization as evidenced by metallographic inspection and mechanical property determination. Figure 8 shows the 
LMP plot for both wrought and heat-treated, and laboratory as-cast, homogenized, and heat-treated versions of alloy 263 .

\subsection{Example 3: NIMONIC ${ }^{\circledR}$ Alloy 105}

NIMONIC ${ }^{\circledR}$ Alloy 105 , hereafter alloy 105 , is yet another well-established Ni-based superalloy with a nominal composition of $\mathrm{Ni}-14.8 \mathrm{Cr}-20.0 \mathrm{Co}-5.0 \mathrm{Mo}-1.2 \mathrm{Ti}-4.7 \mathrm{Al}$ with small amounts of $\mathrm{C}$ and $\mathrm{B}$ and limitations on $\mathrm{Cu}, \mathrm{Fe}, \mathrm{Mn}, \mathrm{Si}$, and $\mathrm{Zr}$ (Ref 16). Small-scale ingots of this alloy were produced with resultant maximum sdas $\leq 100 \mu \mathrm{m}$. The homogenization cycle used in this case was $1100{ }^{\circ} \mathrm{C} / 3 \mathrm{~h}+1200{ }^{\circ} \mathrm{C} / 9 \mathrm{~h}$. Good homogenization was achieved (see Fig. 9). Figure 10 shows the resultant creep testing that was performed on the cast, homogenized and heat-treated alloy 105. As with the Haynes

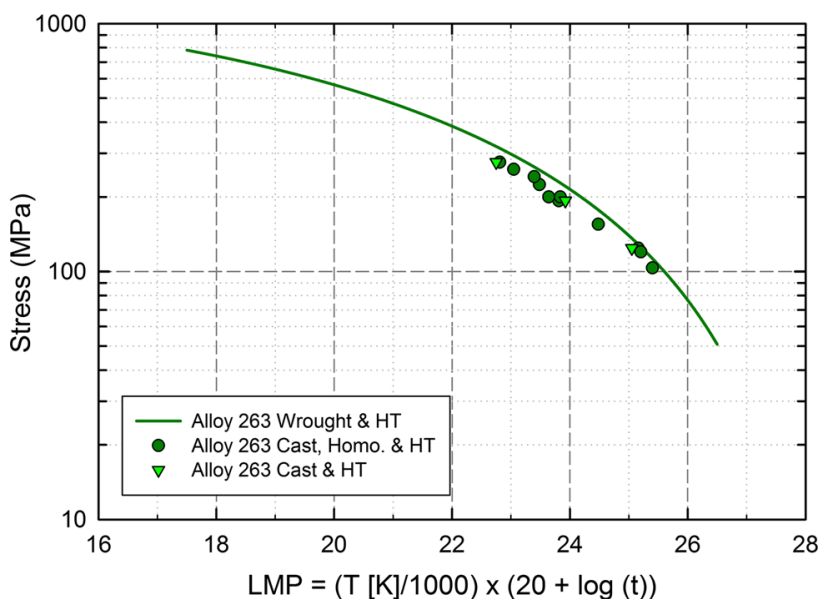

Fig. 8 Larson-Miller parameter plot for alloy 263 comparing the cast and heat-treated (inverted triangles) to cast, homogenized and heat-treated (solid circles) to that of the wrought-processed and heattreated (solid line). Note that the cast, homogenized, and heat-treated version of alloy 263 compares favorably to that of the wrought version of alloy 263 in terms of creep rupture life, while those tests of the as-cast and heat-treated version generally do not. (Wrought data on creep were extracted from a variety of references, e.g., Ref 15)
282 alloy, there was good correlation between wrought and ascast/homogenized/heat-treated creep rupture lives for stresstemperature combinations.

\subsection{Examples 4: Stainless and Ferritic/Martensitic Steels}

The use of the homogenization algorithm can be applied to stainless steels with equally effective results. For example, ferritic stainless steel 441, which has a nominal composition of $\mathrm{Fe}-18.5 \mathrm{Cr}-0.5 \mathrm{Nb}-0.3 \mathrm{Ti}$, and also has limits on $\mathrm{Mn}, \mathrm{Si}, \mathrm{Ni}$, and other minor elements, was evaluated similarly to the previous examples. Small-scale laboratory ingots of this alloy were produced with resultant maximum sdas $\leq 100 \mu \mathrm{m}$. The homogenization cycle used in this case was $1100{ }^{\circ} \mathrm{C} /$ $3 \mathrm{~h}+1200{ }^{\circ} \mathrm{C} / 9 \mathrm{~h}$, since the initial incipient melt temperature was about $1300{ }^{\circ} \mathrm{C}$. Good homogenization was achieved.

More complicated ferrous alloys such as ferritic/martensitic steels contain more elements (upwards of 12), some of which are hard to diffuse elements such as Mo and W. Additionally, this class of alloys is generally austenitic at the high heat treatment temperature. It is well known that elements diffuse more slowly in the austenitic phase than they do in the ferritic phase, thus alloys having the austenitic phase as the hightemperature phase are more difficult to successfully homogenize. Nevertheless, the homogenization approach discussed herein has been applied to small-scale ingots of ferritic/martensitic alloys which had resultant maximum sdas $\leq 100 \mu \mathrm{m}$. In one example, the initial incipient melt temperature was $1193{ }^{\circ} \mathrm{C}$. The homogenization cycle used for this case was $1125^{\circ} \mathrm{C} / 1 \mathrm{~h}+1250{ }^{\circ} \mathrm{C} / 8 \mathrm{~h}$. After the first temperature hold, the new incipient melt temperature was calculated to have risen to slightly over $1300{ }^{\circ} \mathrm{C}$, thus allowing the application of the second higher hold temperature to successfully complete alloy homogenization. The effectiveness of this treatment was evident when comparing the creep performance of the homogenized alloy to similar commercial alloys within this class of materials (i.e., those alloys having similar although not exact chemical compositions). At $650{ }^{\circ} \mathrm{C}$ and $25 \mathrm{ksi}$ applied stress for the creep test, the homogenized alloy had a life of $1618 \mathrm{~h}$ while similar commercial alloys had lives ranging between 614 and $655 \mathrm{~h}$. The improved performance became even more dramatic as the applied stress was reduced to $20 \mathrm{ksi}$ and the time under creep conditions increased. The homogenized alloy had a life of

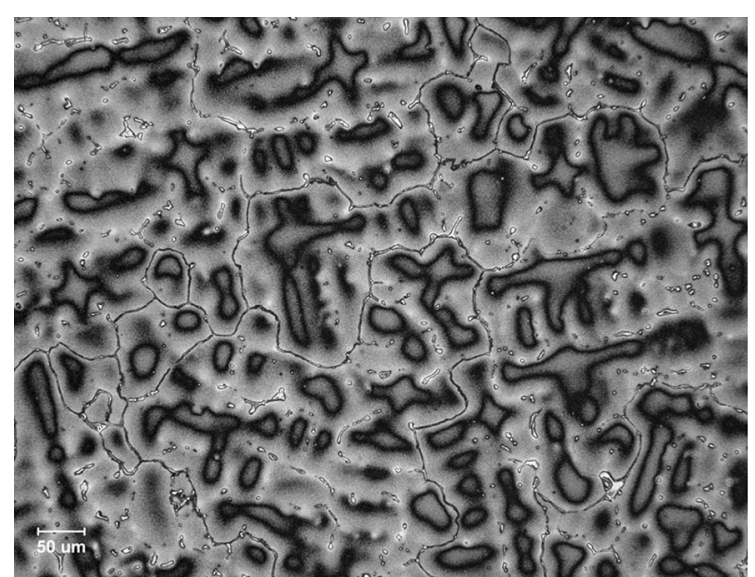

(a)

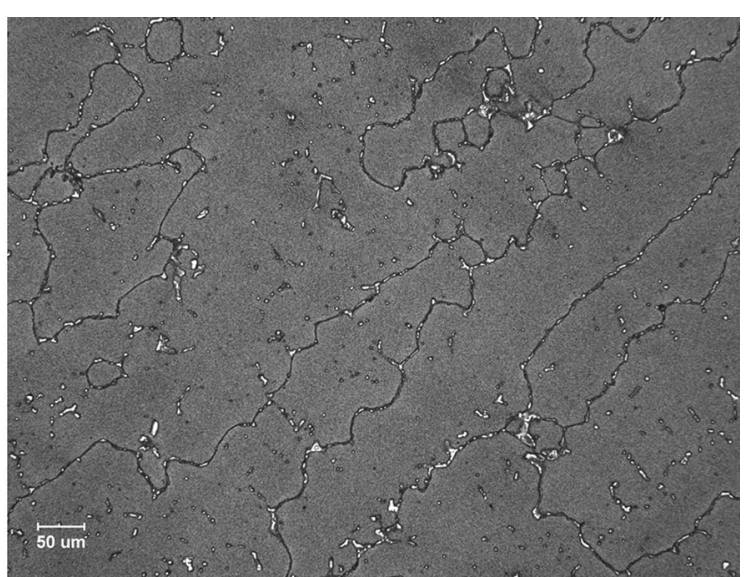

(b)

Fig. 9 Examples of the as-cast (a) and homogenized (b) microstructure of Nimonic 105. Dendritic coring (i.e., element segregation) is clearly visible on the left, while only grain boundaries and carbides are visible on the right. Micron markers indicate $50 \mu \mathrm{m}$ 
$5388 \mathrm{~h}$, while the commercial alloy lives ranged from 1783 to $2428 \mathrm{~h}$, perhaps demonstrating the benefit of a chemically uniform microstructure.

\section{Discussion}

Obtaining good mechanical properties for thick-wall castings of nickel superalloys and ferritic/martensitic alloys is very important in the power industry. For land-based power plants that will be operated at $760{ }^{\circ} \mathrm{C}$ and $34.5 \mathrm{MPa}$, for example, superior-heat-resistant materials will be needed. Superior creep strength will be needed for these components to reach at least $100,000 \mathrm{~h}$ in service, if not longer. Most commercial gas turbine nickel-based castings are in relatively thin sections compared to the steam turbine high- and intermediate-pressure rotor casings or chests that house the main steam valves porting into the rotors. As such normal investment casting techniques traditionally used for nickel superalloys in gas turbines are not appropriate. Additionally, the slow cooling in these thicksection castings leads to significant segregation that must be addressed if the full potential in terms of strength and creep life is to be realized. Furthermore, because of the size scale of these machines and the high cost of Ni alloys, the use of Fe alloys will also have to be extended to the highest possible temperatures as well. The homogenization approach described herein allows these goals to be achieved.

NETL examined the technology gap in thick-wall nickel superalloy casting and approached it using modified nickel compositions proven to succeed in the wrought form. It was quickly determined that in order to achieve similar mechanical properties segregation in the solidified nickel castings needed to be addressed, especially when solution/age heat treatments failed to sufficiently improve the strength and creep life to levels needed in A-USC steam cycles. NETL envisioned an approach where the best thermodynamic and kinetic property data were used to develop a computationally based heat treatment cycle in which a physical feature, i.e., the sdas, was

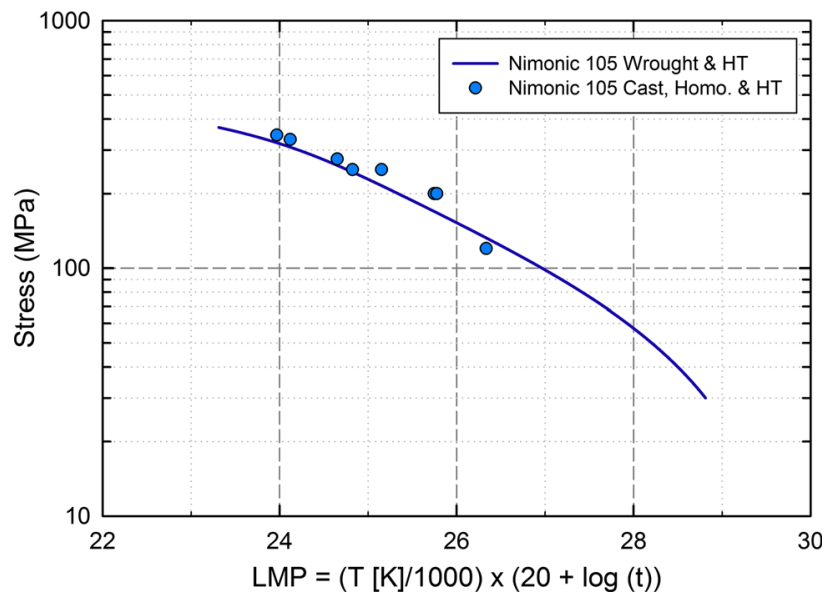

Fig. 10 Larson-Miller parameter plot comparing the cast, homogenized, and heat-treated (closed circles) vs. wrought and heat-treated version of Nimonic 105 (solid line). Note that the cast, homogenized, and heat-treated version on Nimonic 105 compares favorably to that of the wrought and heat-treated alloy. [Wrought data on creep were extracted from a variety of references, e.g., Ref 16, as well as from actual testing of Nimonic ${ }^{\circledR}$ Alloy 105 (Ref 19)] used as a "physical feature of merit" in order to derive the multi-step homogenization cycle. Furthermore, Eqs 1 and 2 fully describe the incremental solid chemistry in such a way that it is possible to describe the positional chemistry independent of the phases that form during solidification. This is very useful in cases where slow-diffusing elements are involved and tend to segregate to second phases (e.g., Mo or Nb in Ni alloys) or in the case of the solidification of a matrix phase that is partially BCC and then FCC as is often the case with ferritic/martensitic alloys. In order to test this approach, a number of nickel superalloys proven to perform well in A-USC conditions have been produced as small-scale laboratory castings, but done in such a way as to simulate the cooling in thicker-wall castings. These castings were homogenized to the highest degree possible based on the approach described herein before subsequent traditional heat treatments used for these alloys.

It has, therefore, been possible to produce cast versions of each of the following nickel superalloys:

a) Nickel solid solution-strengthened superalloys (e.g., Haynes ${ }^{\circledR} 230^{\circledR}$, INCONEL ${ }^{\circledR}$ Alloy 617, and INCONEL ${ }^{\circledR}$ Alloy 625)

b) Gamma prime-strengthened nickel superalloys (e.g., alloy 105, alloy 263, INCONEL ${ }^{\circledR}$ Alloy 740, and Haynes 282)

Adding the homogenization cycle in the production sequence of each of these as-cast alloys has greatly reduced, and/or eliminated completely, alloy segregation due to thicksection cooling from the melt. For the $\gamma^{\prime}$-strengthened alloys (i.e., alloy 105, alloy 263, and Haynes 282 in particular), subsequent aging heat treatments produced mechanical strength equivalent to the wrought product. This was especially evident in the creep rupture test results where life as measured by the Larson-Miller parameter as a function of stress was equivalent to the wrought alloy values. (See Fig. 6 for Haynes 282; Fig. 8 for alloy 264; and Fig. 10 for alloy 105).

On the other hand, solution-strengthened castings (i.e., Haynes ${ }^{\circledR} 230^{\circledR}$, INCONEL ${ }^{\circledR}$ Alloy 617 , and INCONEL ${ }^{\circledR}$ Alloy $625)$ continue to exhibit a debit in terms of creep capability compared to the wrought version of the alloy, and this is most probably due to a lack of retained process strain from thermomechanical processing which can facilitate global microstructural changes in the alloy. This is shown in Fig. 11 for INCONEL $^{\circledR}$ Alloy 625. The creep performance of these solution-strengthened superalloys clearly shows that the creep capability trends with that of the wrought alloys but is less than that of the wrought version of the alloy at high stress. This behavior is consistent with the differences that may result when a solid-solution alloy is not thermo-mechanically processed. Since there are little or no $\gamma^{\prime}$ precipitates in these alloys, the lack of strength in the absence of thermo-mechanical processing (TMP), and subsequent heat treatment, cannot be compensated for without-chemistry modification.

The effect in solution-strengthened nickel superalloys is complicated in that an FCC alloy derives initial yield stress from the amount of retained cold work after TMP and subsequent heat treatment (Ref 20). INCONEL ${ }^{\circledR}$ Alloy 625 is available in two forms: Grade 1 and Grade 2. Grade 1 possesses a higher yield stress ( $>60 \mathrm{ksi}$ in sections up to $100 \mathrm{~mm}$ diameter) compared to Grade 2 (>40 ksi for sections sizes comparable to Grade 1, and larger). This is due in part to postTMP heat treatment. For Grade 1, the TMP processed alloy is 


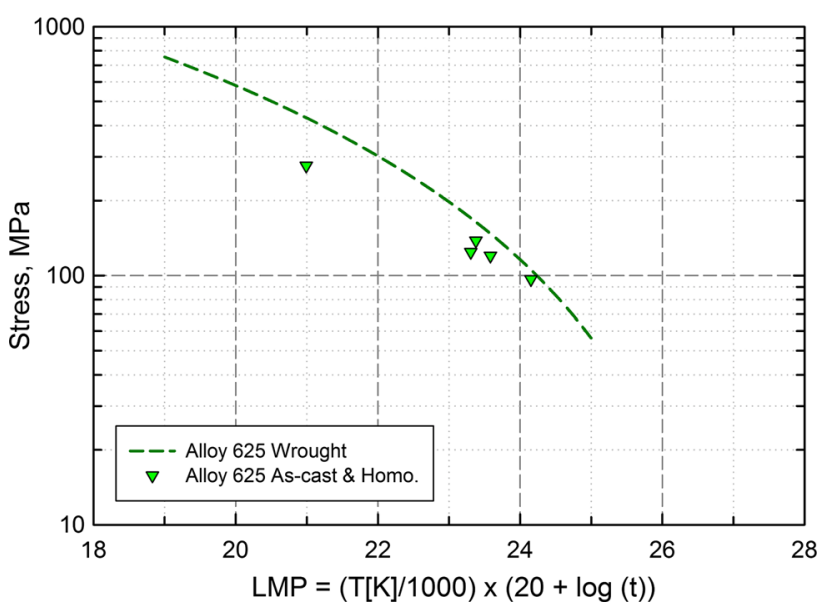

Fig. 11 Larson-Miller parameter plot comparing the cast and homogenized (closed inverted triangles) vs. wrought and heat-treated version of Alloy 625 (dashed line). Note that the cast and homogenized 625 variant deviates from the wrought LMP for 625 at the higher stress levels. [Wrought data on creep were extracted from a variety of references, e.g., Ref 17 for INCONEL ${ }^{\circledR}$ Alloy 617 and Ref 18 for INCONEL ${ }^{\circledR}$ Alloy 625]

given a company-specific mill anneal treatment after processing, which is usually at a temperature less than what is used for complete solution anneal (i.e., both time and temperature). In the Grade 2 variant, the TMP processed article is given a full solution anneal (i.e., longer time and higher temperature compared to Grade 1). Consequently, residual strain due to dislocation density is different in each case. Grade 1 has more of both than does Grade 2. This is particularly relevant to FCC solution-strengthened cast alloys. After the homogenization step, the matrix is both low in residual strain and low in dislocation density. This influences creep strength, particularly at high stress levels (or for short-term creep tests, which were the screening tests run in this research) because the initial dislocation network is absent and must build itself up at the same time it changes due to creep. Thus, at relatively high stress levels, FCC solution-strengthened nickel alloys in the cast form cannot match the creep life of the wrought analog. At the creep temperature $\left(800{ }^{\circ} \mathrm{C}\right)$ and lower stress, the creep performance of the cast 625 is closer to the value of the wrought product (Fig. 11). It is unclear that if lower temperatures and lower stresses were used in the creep rupture tests whether the LMP value of the casting would approach that of the wrought product.

Although not shown here, tensile mechanical behavior at $800{ }^{\circ} \mathrm{C}$ of the solution-strengthened cast and homogenized and the $\gamma^{\prime}$-strengthened cast, homogenized and heat-treated superalloys was considered to be very good, especially in terms of ductility measures. Typically, elongation-to-failure for the solution-strengthened cast and homogenized superalloys was at least $20 \%$, or greater. For the $\gamma^{\prime}$-strengthened alloys, elongation-to-failure for tensile tests performed at $800{ }^{\circ} \mathrm{C}$ was around $15 \%$, or greater, for alloys alloy 105 , alloy 263 , and Haynes 282.

In ferrous alloys, the improvement in creep performance of 9-12\% Cr ferritic-martensitic steels that have been given a homogenization cycle prior to thermo-mechanical processing is most likely due to greater uniformity in the distribution of elements. This is particularly important for this class of materials since they are susceptible to the formation of strength-reducing phases (e.g., Laves and Z-phase) when exposed to high temperatures over extended periods. Regions of possible chemical inhomogeneity, leading to pockets of difficult-to-diffuse elements like $\mathrm{W}$ or $\mathrm{Mo}$ or $\mathrm{Co}$, provide opportunities for these undesirable phases to form relatively early in their creep life (compared to their expected 30-year operating life).

A number of other observations were made during the course of homogenization modeling simulations, experimental manufacturing on the laboratory and commercial scales, and mechanical property verification activities for nickel superalloys. During the computational modeling activities, it was found that certain refractory elements, including $\mathrm{W}, \mathrm{Mo}$, and $\mathrm{Nb}$, do not homogenize even after $\sim 22 \mathrm{~h}$ at $1100{ }^{\circ} \mathrm{C}$. This was the primary motivation for exploring and developing a computational multi-step homogenization heat treatment cycles. Also, it was observed during optical microscopy and SEM of the cast structures that segregation of the second-phase strengthening elements, including $\mathrm{Al}, \mathrm{Nb}$ and $\mathrm{Ti}$, consistently occurred in these alloys, to the point that half to two-thirds of the casting could be considered "lean." It was also during these early microstructural investigations that $\mathrm{Cr}$-poor regions were discovered in the solidified casting as predicted by the thermodynamic modeling activities. In selected alloys, significant Co segregation was also predicted, and as such had to be addressed. Thermodynamic modeling suggested that significant partitioning of $\mathrm{Mn}$ and $\mathrm{Si}$ to the interdendritic region might also occur. These many factors made apparent the need to homogenize these materials since to one degree or another, some or all of the above factors came into play for each of the nickel superalloy castings. It is apparent from the evidence presented that to produce consistent tensile and creep properties a more uniform microstructure in terms of the chemical distribution of elements is needed. Other manufacturing factors, such as shrinkage, voids, and other melt-solidification anomalies, consistent with thick castings, still occurred. While important to note, these manufacturing-related anomalies are best addressed through optimization of the melting and casting practices upon scale-up.

\section{Summary and Conclusions}

The application of carefully controlled multi-step homogenization cycles, based on thermodynamics, kinetics, and measurement of the physical feature of merit, i.e., sdas, was achieved through application of a specific computational algorithm, and was used to significantly reduce, and/or eliminate, visible elemental segregation in slow-cooled nickel and steel castings. As a consequence, tensile mechanical properties for these alloys were more consistent and creep rupture life was greatly improved as were particular measures of ductility for both tensile and creep-tested specimens.

Creep life for computationally homogenized $\gamma^{\prime}$-strengthened nickel superalloy castings has been shown to be equivalent to fully wrought versions of the same alloy. Solution-strengthened superalloys (e.g., Haynes $230^{\circledR}$, INCONEL ${ }^{\circledR}$ Alloy 617, and INCONEL ${ }^{\circledR}$ Alloy 625), while performing well in the cast and homogenized condition, did not perform to quite the same level as their wrought counterpart. This resulted because the grain structure could not be controlled to the same degree as in the 
wrought variants and because retained strain, and hence, dislocation density, was very low. Similar good tensile and creep behavior have also been observed for the 9-12\% $\mathrm{Cr}$ ferritic-martensitic steel castings, where especially creep life has been significantly improved.

\section{Acknowledgments}

The authors would like to thank Mr. Edward Argetsinger and Mr. Joseph Mendenhall for assistance in melting and heat treating as well as Mr. Paul Danielson for metallographic work.

\section{References}

1. D.A. Porter and K.E. Easterling, Phase Transformation in Metals and Alloys, Van Nostrand Reinhold Co., New York, 1981, p 208

2. H.K. Danielsen, P.E.D. Nunzio, and J. Hald, Kinetics of Z-Phase Precipitation in 9 to 12 pct Cr Steels, Metall. Mater. Trans. A, 2013, 44, p 2445-2452

3. G.L. Erickson, The Development and Application of CMSX-10, Superalloys 1996, R.D. Kissinger, D.J. Deye, D.L. Anton, A.D. Cetel, M.V. Nathan, T.M. Pollock and D.A. Woodford, Ed. TMS, Warrendale, PA, 1996, p 35-44

4. E.C. Caldwell, F.J. Fela, and G.E. Fuchs, Segregation of Elements in High Refractory Content Single Crystal Nickel Based Superalloys, Superalloys 2004, K.A. Green, T.M. Pollock, H. Harada, T.E. Howson, R.C. Reed, J.J. Schirra, and S. Walston, Ed. TMS, Warrendale, PA, 2004, p 811-818

5. S.R. Hedge, R.M. Kearsey, and J.C. Beddoes, Designing Homogenization-Solution Heat Treatments for Single Crystal Superalloys, Mater. Sci. Eng., A, 2010, 527, p 558-5538

6. P.D. Jablonski and C.J. Cowen, Homogenizing a Nickel-Based Superalloy: Thermodynamic and Kinetic Simulation and Experimental Results, Metall. Mater. Trans. B, 2009, 40, p 182-186
7. P.D. Jablonski and C.J. Cowen, Computationally Optimized Homogenization Heat Treatment of Metal Alloys, S119,015 and S130,803

8. J.O. Andersson, T. Helander, L. Höglund, P.F. Shi, and B. Sundman, Thermo-Calc and DICTRA, Comput. Tools Mater Sci., Calphad, 2002, 26, p 273-312

9. Henrik Larsson and Lars Höglund, Multiphase Diffusion Simulations in 1D Using the DICTRA Homogenization Model, Calphad, 2009, 33, p 495-501

10. E. Scheil, Bemerkungen zur schichtkristallbildung, Z. Metallkd., 1942, 34, p 70-72 ((in German))

11. G.H. Gulliver, The Quantitative Effect of Rapid Cooling Upon the Constitution of Binary Alloys, J. Inst. Met., 1913, 9, p 120-157

12. P.D. Jablonski, J.A. Hawk, C.J. Cowen, and P.J. Maziasz, Processing of Advanced Alloys for A-USC Steam Turbine Applications, Proceedings of the 6th International Conference on Advances in Materials Technology for Fossil Power Plants, D. Gandy, J.P. Shingledecker, and R. Viswanathan, Ed. Palo Alto, CA, Electric Power Research Institute, 2010, p 872-885

13. P.D. Jablonski, J.A. Hawk, C.J. Cowen, and P.J. Maziasz, Processing of Advanced Cast Alloys for A-USC Steam Turbine Applications, JOM, 2012, 64, p 271-279

14. Haynes International, Haynes ${ }^{\circledR} 282^{\circledR}, \mathrm{H}-3173 \mathrm{~A}(2008), 28 \mathrm{p}$

15. Special Metals Corporation, Nimonic ${ }^{\circledR}$ Alloy 263, SMC-054 (2004), $11 \mathrm{p}$

16. Special Metals Corporation, Nimonic ${ }^{\circledR}$ Alloy 105, SMC-081 (2007), $18 \mathrm{p}$

17. Special Metals Corporation, INCONEL ${ }^{\circledR}$ Alloy 617, SMC-029 (2009), $12 \mathrm{p}$

18. Special Metals Corporation, INCONEL ${ }^{\circledR}$ Alloy 625, SMC-063 (2006), $20 \mathrm{p}$

19. R. Viswanathan, J.A. Hawk, R.C. Schwant, D. Saha, T. Totemeier, S. Goodstine, M. McNally, and D.B. Allen, Steam Turbine Materials for Ultrasupercritical Coal Power Plants, Final Technical Report, DOE DEFC26-05NT42442/OAQDA-OCDO 05-02(B), November 5, 2009, $535 \mathrm{p}$

20. J.A. Hawk, NiCrMoCb Alloy with Improved Mechanical Properties, US 8,101,122 B2, January 24, 2012 